\title{
Stout on Relativism, Liberalism, and Communitarianism
}

\author{
MICHAEL J. QUIRK \\ Pace University
}

In Ethics After Babel,1 Jeffrey Stout has advanced and defended two interrelated theses: first, that Davidsonian insights effectively subdue many forms of ethical relativism, second, that if relativism, skepticism, and nihilism are effectively dissolved by semantic holism, then the possibility, announced by communitarians such as Bellah and Maclntyre, that liberal individualism might lack any resources to sustain rational moral discourse is, at best, overstated, and at worst, unintelligible. In this essay I shall argue that although Stout's analyses of conceptual and alethic relativism are largely correct, they do not support his conviction that "liberal modernity" is a sociological fiction. On the contrary, it is only because relativism has been transcended in the work of such philosophers as Davidson, Gadamer, Rorty, and Stout himself, that one can see why intractable moral and political dispute is 80 much a part of contemporary social life.

Stout's allusion to Babel is largely deflationary: he believes that the mere facts of fundamental moral disagreement and conceptual diversity do not automatically cement the cases of moral skeptics, nihilists, or relativists. He invites us to view the debate between ethical universalists and their adversaries as bedeviled by a misleading either/or. Universalistic moral epistemologists, such as Gewirth and Donagan, as well as relativists such as Wong and Harman, confront us with the option of construing morality either as accessible to pure practical reason as such, or as irreducibly particularized and unique. There is reason to suspect, Stout argues, that this taken-for-granted dichotomy is theoretically and practically unsupportable.

Stout's via media between universalism and particularism draws heavily upon the work of Donald Davidson, who, in Inquiries into Truth and Interpretation, 2 established two important semantic truths. First, the idea of a conceptual framework or grid which either organizes or conforms to some preconceptual content is vacuous: that content is either specifiable and determinate, in which case it is not preconceptual, or it is not specifiable or determinate, and thus one is given no good reason to believe in it. Here Davidson simply updates and gives an analytic twist to Hegel's dismissal of Kant's ding-an-sich as both unintelligible and superfluous. Second, and more importantly, Davidson reveals the

1 Beacon Press: Boston, 1988.

2 The Clarendon Press: Oxford, 1984. 
absurdity of "radically incommensurable conceptual schemes," conceived as mutually untranslatable languages. Entire languages which supposedly share no meanings in common can express no common beliefs, which neatly evades the issue of why one would choose to understand such collections of physical and acoustic tokens as languages. If beliefs about a given meaningful term in an alien language differ en masse from those attaching to its cognate in one's native language, wisdom would dictate not the ascription of "radically incommensurable" meanings or totally discrepant beliefs to speakers of the alien tongue but the revision of one's translation manuals, for what one singles out as the cognate term is simply not what is meant by the aliens, and thus cannot be a genuine cognate. $3^{3}$

Thus it flies in the face of interpretive charity to impute massive disagreement between languages in any truth-conditional theory of meaning, where meaning is determined by the distribution of beliefs expressed in T-sentences. Relativists, however, to the extent that they deny the possibility of transcultural and/or translinguistic judgments, must insist upon the possibility of the "total occlusion" of beliefs and meanings between different cultures, societies, and cognitive systems. Insofar as this cannot be reconciled to the most basic demands of radical translation, the relativist lacks even the most rudimentary case to refute. The sheer existence of conceptual diversity and conflict of beliefs does not of itself make relativism theoretically attractive, and does not preclude the possibility of the practical resolution, through what Stout calls "hermeneutic enrichment" or moral "bricolage," of whatever epistemic conflicts or conceptual inadequacies that might arise. 4

Davidsonian holism is important in another respect, Stout argues: it throws into question a number of the constants that have haunted the debate between Liberals and Communitarians. Stout relies upon Rorty's description of "philosophical liberals" as those for whom the priority of right over good, or procedure over substantive visions of the good, is a matter of universal principle discovered and justified by an adequate moral epistemology. 5 Insofar as this is foundationalism applied to politics, it stands under the shadows cast by the Davidsonian and Gadamerian holism which Stout uses to such advantage against moral relativism.

But communitarians use another tactic against liberal society and politics, one which draws upon holistic arguments similar to those used by Stout in his polemic against relativism. If moral meanings and beliefs are

3 "On the Very Idea of a Conceptual Schemen, in Inquiries, pp. 183-98. See also Ian Hacking, Why Does Language Matter to Philosophy, (Cambridge: Cambridge Univ. Press, 1975), pp. 129-156.

4 This is the topic of Chs. 1-4 of Stout's book.

5 Richard Rorty, "Postmodernist Bourgeois Liberalism", in R. Hollinger, ed., Hermeneutics and Praxis (Notre Dame: Univ. of Notre Dame Press, 1985), pp. 214-17. 
holistically determined, then the foundationalist task of grounding moral convictions and judgments in explicit universal principles is as misguided as Cartesian epistemology, for essentially the same reasons. So any coherent community of moral agents must evince a substantial consensus about the nature of a humanly good life and its corresponding obligations. But liberal society, predicated as it is on the impossibility of such consensus and the undesirability of a politics based upon a shared vision of the good, prohibits such a consensus, or at least makes it politically and socially irrelevant, and in so doing robs the culture of any coherent moral discourse. Thus Alasdair Maclntyre argues that liberal society cannot be other than "civil war carried on by other means" and that its inception marked a catastrophic shattering of the theoretical and practical comprehension of morality; and Michael Sandel complains that it rests upon an impossible metaphysics of the self, prior to and unencumbered by its particular attributes, desires, or beliefs. 6

Stout responds to the above by reaffirming the tenets of Davidsonian holism. If the idea of radically incommensurable conceptual schemes is incoherent, and if any two intertranslatable languages must therefore agree in large measure about what propositions are true, then the communitarian fear that rational moral discourse is stymied by liberal society's wild plurality of moral standpoints is quite misplaced. The predicament alleged by Macintyre to embroil all modernity cannot be as dire as he insists, since no disagreement is a priori irresolvable, given the need for some shared common ground of belief between contending parties. And even if one party to a moral dispute lacks key moral terms or concepts available to her counterpart, she still has the option to incorporate--or reject--this alternative moral vocabulary through "hermeneutic enrichment" or "moral bricolage." Things cannot be hopeless in principle, as Macintyre suggests.7

Stout, in effect, coopts the communitarian critique by painting liberalism in communitarian colors: there is enough moral consensus within liberal social and political orders to sustain rational debate, and this consensus is not incompatible with liberal pluralism and neutralism. The consensus characteristic of liberalism is a "thin consensus," one based upon an army of platitudes and the well-entrenched creole dialect of "human rights," which Stout believes travels well across many substantively different conceptions of the good. The problems that do beset the liberal order-the corruption of practices by external goods such as money, status and power-are thus not unique to liberal society, nor are they caused by liberal theory or practice, nor are they insoluable on liberalism's

6 Alasdair Maclntyre, After Virtue (Notre Dame: Univ. of Notre Dame Press, 1981), p. 236; Michael Sandel, Liberalism and the Limits of Justice (Cambridge: Cambridge Univ. Press, 1982).

7 See Ch. 9 of Ethics After Babel, passim. 
own terms. 8 The liberal modernity excoriated by communitarians such as MacIntyre, Sandel, Bellah, and Lasch, turns out to be a myth, inspired by a "terminal wistfulness" for an equally mythic social cohesiveness.

Stout's optimistic appraisal of liberal society is partly a product of the way in which he appropriates Davidson's Truth-conditional theory of meaning. Because Davidson has shown the Scheme/Content distinction to be untenable and has eliminated at least one version of "radical incommensurability" from the holist's lexicon, Stout surmises not only that the theoretical basis for relativism has been eroded, but that there is enough overlap between moral beliefs and enough resources for hermeneutic enrichment to make the rational resolution of moral differences a human possibility. Yet Stout overinflates Davidson's actual achievement, and in doing so, does not recognize serious obstacles to achieving a meaningful moral consensus in the liberal order.

Davidsonian translation is a technique of fixing meanings by mapping beliefs and cross-indexing them with an already-articulated system of beliefs--that which resides in one's own language. "Truth" is taken as a logically primitive term in any language; and the principle of charity enjoins one to try to honor the fact that most of the targetlanguage's propositions will be true. Yet in actual linguistic practice, truthascriptions are inextricable from verification and assertibility norms; truthascriptions are embedded in historical and practical contexts of justification. The absence of such pragmatic concerns from truthconditional semantics leads one to question not its accuracy or coherence as a research program, but its adequacy and its sufficiency. For if the assignment of truth values to interpreted sentences is, at base, a practical task, one should acknowledge that the contours of one's practices have a bearing upon the truth value assigned. 9 Davidson conspicuously fails to do this. Truth-conditional semantics is methodologically unconcerned with the actual practical contexts of belief. It begins with the assumption that since both languages in a T-theory cannot be in massive disharmony, one can assume that the task of understanding the target language is simply a matter of coordinating the beliefs it expresses with one's own language's key beliefs. Davidson thus leaves one with the impression that any given task of translation can be accomplished solely with the resources

8 See Ch. 10 of Ethics After Babel, passim.

9 See, g., Michael Dummett, "Truth", in Truth and Other Enigmas (Cambridge: Harvard Univ. Press, 1978), and Charles Taylor, "Theories of Meaning", in Human Agency and Language: Philosophical Papers, vol. 1 (Cambridge: Cambridge Univ. Press, 1985). 
one's own singular language affords prior to the act of translating. $10 \mathrm{He}$ seems to claim not only that no language is untranslatable-in-principle, but that any language can be translated into any other as it may exist at any given moment. Furthermore, it is taken for granted by Davidson that the holistic background presupposed by a T-theory is likewise a network of explicit beliefs, and that any and all such beliefs can and will, as the Ttheory nears completion, be enumerated. Language is fundamentally a locus of belief for Davidson.

This methodological fixation conceals a large and, I think, unexamined assumption: that interpreting a language can be understood adequately and exclusively on the model of determining explicit beliefs. This assumption has been explored and challenged by Hubert L. Dreyfus in "Holism and Hermeneutics.11

Dreyfus begins by contrasting the theoretical holism of Quine, Davidson, Husserl, and Feyerabend with the practical holism of Heidegger, Wittgenstein, Merleau-Ponty, and Polanyi. The former construe all understanding, whether that of text, persons, or alien cultures and disciplines, as

....making a total theory about a total theory, that is, making a translation into your language of the theory implied in the other person's behavior or language... For Quine and Davidson all one needs in order to understand another culture or epoch is a theory that maximizes agreement as to which beliefs are true and which are false. The fact that these beliefs only make sense in a practical situation against a taken-for-granted cultural background seems to them to present no special problem, since on their view the background can itself be made the explicit object of some form of theoretical detached analysis revealing further beliefs. 12

10 For critiques of Davidson along these lines, see Hilary Putnam, "Truth and Convention: On Davidson's Refutation of Conceptual Relativism", in M. Krausz, ed., Relativism Interpretation and Confrontation (Notre Dame: Univ. of Notre Dame Press, 1989); Joseph Margolis, "Rationality and Realism", Ch. 4 of Pragmatism Without Foundations (Oxford: Basil Blackwell, 1986), and "Truth and Relativism" in Science Without Unity (Blackwell, 1987); Alasdair MacIntyre, "Tradition and Translation", Ch. XIX of Whose Justice? Which Rationality? (Notre Dame: Univ. of Notre Dame Press, 1988).

11 In Hollinger, op. cit., pp. 227-48.

12 Dreyfus, pp. 230-31. 
Yet recent attempts to do precisely that (most notably, Husserl's Crisis and the formalist programs in Artificial Intelligence) have floundered within the vastness and indeterminacy of this non-formal cultural background. 13 Husserl's verdict on Crisis style phenomenology, that its eidetic reductions constitute an "infinite task," amounts to an admission of failure, given his ambitions to set philosophy on the path of a strict science. If understanding can never be brought to some sort of rest, however temporary, nothing has been understood. And, Dreyfus suggests, this accounts for the nihilism that occasionally and unexpectedly crops up in theoretical holists confronted with the problems of the rationality and truth-value of coherent alternative theories: eg., Feyerabend's dismissal of the rational superiority of competing paradigms, or Derrida's celebration of textual "play" over interpretive seriousness. 14

Practical holists avoid the problems of indeterminacy and nihilism by understanding interpretation as a practical, rather than a theoretical epistemological problem:

...What makes up the [cultural] background is not beliefs, either explicit or implicit, but habits and customs, embodied in the sort of subtle skills which we exhibit in our everyday interactions with things and people... Thus our knowledge, even our attempts to know the background, is always already shaped by what might be called our implicit ontology, an "ontology" which is in our practices as ways of behaving towards things and people, not in our minds as background assumptions which we happen to be taking for granted. 15

Genuine understanding and criticism of that which is foreign to us thus cannot simply be a matter of charting beliefs and/or behavioral rules:

According to the ontological hermeneutics of both Heidegger and Wittgenstein, when we understand another culture we come to share its know-how and

13 Much of Dreyfus's recent work documents these failures. See his introduction to Husserl, Intentionality, and Cognitive Science (Cambridge: M.I.T. Press, 1982); H. Dreyfus and S. Dreyfus, "Making a Mind Versus Modeling the Brain: Artificial Intelligence Back at Branchpoint" in S. Graubard, ed., The Artificial Intelligence Debate (Cambridge, M.I.T. Press, 1988); and H. Dreyfus and J. Haugeland, "Husserl and Heidegger: Philosophy's Last Stand" in Michael Murray, ed., Heidegger and Modern Philosophy (New Haven: Yale Univ. Press, 1978).

14 Dreyfus, "Holism and Hermeneutics", pp. 228, 242.

15 Dreyfus, p. 232. 
discriminations rather than arriving at agreement concerning which assumptions and beliefs are true. This coordination comes about not by making a translation, or cracking a code, but by prolonged everyday interaction; the result is not a commensuration of theories but what Heidegger calls "finding a footing" and Wittgenstein refers to as "finding one's way about."16

The context of agreement for radical translation, and by extension, for any effective rational argument, is not merely that of belief, nor can it be primarily that of belief. The "agreement in judgement" of which Wittgenstein speaks in the Philosophical Investigations 17 is made possible against a background of skills and practices, which cannot' be exhaustively formalized as a system of explicit beliefs or formal rules without risking an infinite regress. To translate a language is to have already, in some unspecified sense, articulated a set of culturallyincarnate intentions as a belief system, and this entails a prior, tacit grasp of shared aims and embodied skills-of Heidegger's Vorhaben and Wittgenstein's Lebensformen.

Thus the task of reaching a rational consensus between speakers of these alternative languages, between partisans of different cultures, paradigms, or less-than-radically incommensurable conceptual schemes, is therefore contingent not only upon "the impossibility of massive [theoretical] error," but upon the extent and quality of this deeper practical agreement. The success or failure of any particular attempt at the rational resolution of conflict will reflect the extent and the nature of "agreement in judgement" between the parties to the debate. But neither theoretical nor practical holism eliminates the possibility that in certain specific cases, no genuinely rational consensus can be forged, because the beliefs in a given shared subject matter are too disparate, or too formal and indeterminate, and more significantly, because the practices whereby the heterogeneity of beliefs and meanings can be overcome are either nonexistent, feeble, or corrupted by ideology into mere simulacra of rational activities. How would one be able to determine when this is so?

\section{III}

One way would be to outline the conditions for the resolution of meaningful disagreements and the corresponding ways in which nonmeaningful disagreements--cases of "incommensurable moral vocabularies"--can be attenuated through the process of "hermeneutic

16 Dreyfus, p. 235.

17 Philosophical Investigations (London: Macmillan, 1953), Pars. 241-42, pg. 88. 
enrichment." 18 Let us for the moment assume a requisite "thin consensus" on moral platitudes in the social and political orders, and that this suffices to make most moral disagreements within that order meaningful, rather than merely verbal. The rational resolution of moral conflict would consist in a backwards appeal from those specific moral convictions to more general ones which can provide the former with more or less adequate rational support. 19 The appeal which provides the most adequate support to a given moral position is the one which commands rational assent, and if no single appeal can be established as rationally superior, the debate proceeds until one is formulated. This sort of argumentation, insofar as it involves the synthesis of more general reasons-for-action in novel and ad hoc ways, is not strictly deductive but phropetic; nevertheless, the dispute is resolved by a process of commensuration rather than reformulated through hermeneutic enrichment. 20 It takes place within the parameters of a single moral paradigm or vocabulary.

It becomes clear to anyone who has participated in such disputes that principles of too great a generality cannot effectively help in resolving the moral disagreement. Were someone to refer to "One may not do evil to promote good" in order to condemn a specific act of indiscriminate political terrorism against an unjust regime, one might not accomplish much even if there was universal consensus both upon the truth-value of that sentence and its interpretation. For there may be massive disagreement about the application of this general principle to specific actions: one might retort "Killing those that passively support tyranny is not evil in the first place." Thus highly general moral maxims or beliefs, such as "promote in your actions the general welfare," "be courageous," "respect persons as ends-in-themselves," and "Slavery is wrong" serve the purpose of placing more particular moral convictions into some sort of intelligible, justifiable order, but they themselves provide no guidance for action except in the most extreme circumstances. 21

If meaningful moral disagreements are to be resolved, then either one must appeal to principles of some degree of specificity or the parties to the dispute must be able to take for granted certain inexplicit judgemental skills which would make the application of general norms unproblematic. The moral dispute could be settled if one could assume

$18 \mathrm{My}$ distinction between "commensurable" vocabularies and those needing "hermeneutic" aid owes much to Richard Rorty, Philosophy and the Mirror of Nature (Princeton: Princeton Univ. Press, 1979), pp. 315-56.

19 MacIntyre, Whose Justice?, pp. 71-73.

20 See Albert Jonson and Stephen Toulmin, The Abuse of Casuistry (Berkeley: Univ. of California Press, 1988), pp. 23-46.

21 Stanley Hauerwas and Philip D. Renneson, "Flight from Foundationalism" (Unpublished Manuscript), pp. 14-15. 
agreement upon a stock of relatively specific principles pertaining to the subject matter-principles such as "abortions after the 1st trimester of pregnancy are always prima facie wrong" or "Military strategies that rest upon systematically harming noncombatants are inconsistent with the virtues of justice and courage." Such principles do not deductively determine what is to be done in all circumstances; since they are not rules which determine judgement in all cases, but determinate rules which guide judgement of a kind of case, I shall dub them "middle-level principles," and a loose-but-substantial consensus on them "middle-level agreement."

In the absence of explicit "middle-level agreement," disputes can be resolved through "agreement in judgement," i.e., through the nonformalizable phronetic "background" skills which Dreyfus claims undergird all "agreement in opinions." One can pass directly from an understanding of a moral rule, norm, or virtue to its noncontroversial application in a given case, because one can assume a certain standardization in the judgemental skills of others. Only when this fails, when has no recourse to either "middle-level principles" or "agreement in judgement" can one conclude that the problem of resolving the dispute has become hermeneutic, a case of "incommensurable" vocabularies that are not in "meaningful" discord.

To take a disagreement as an occasion for "hermeneutics" one must be able to view the competing moral party as endorsing a rival system of concepts, descriptions, and beliefs, allegiance to which precludes allegiance to one's own system. 22 In the process of hermeneutically "finding a footing" with the alien vocabulary-of acquiring it as a "second first language" in Alasdair Macintyre's words23_we may find that it complements rather than challenges our own moral language, and thus "enriches" our own moral discourse with its descriptions and "candidates for truth and falsity." On the other hand, we might determine it to be genuinely incompatible, whereupon we need to compare the adequacy of the rival vocabulary in reference to the manifest inadequacies of our own, and vice-versa. Rorty, Kuhn, and Bernstein have all claimed this hermeneutic process of comparative-evaluation-withoutcommensuration for the history of the sciences, and Maclntyre has argued that its narrative dimensions-i.e., it's ability to recount the displacement of one body of theory by another-allow for objective judgments about the relative rational worth of incommensurable scientific paradigms. Unless some version of the fact/value dichotomy is true-and like Stout, I see no

22 Cf. Macintyre, Whose Justice?, Ch. XVIII.

23 lbid., p. 394. 
reason to affirm it--the same sort of hermeneutic process of comparison, incorporation, rejection, and/or replacement holds for ethical discourse. 24

IV

Return now to Stout's claims concerning the "thin" Davidsonian consensus present in liberal individualist society. Stout characterizes this consensus in terms of widely agreed-upon moral platitudes, and the moral creole-dialect of human rights. Yet if platitudes or rights are to be the objects of justificatory appeal in a moral dispute, one should be able to assume either a) a degree of material specificity to them, b) a shared, provisionally fixed interpretation of them, or c) shared phronetic skills to govern their application. Yet each of these conditions is rendered problematic by liberalism itself, insofar as it remains committed to neutrality on the issue of the good as such and in middle-level detail for human beings.

For example, Stout's paradigm cases of platitudes-e.g., "Slavery is wrong"-are profoundly abstract. Insofar as "agreement" on such propositions is "thin" and minimal, the interpretation of its constituent terms remains unsettled (what does one mean by "slavery"?), and the question of its proper application is evaded (is this a case of slavery?). That this is true of much political discourse in liberal individualist societies is manifested by disputes over rights, which seldom are about the existence of specific rights, such as life, liberty, and the pursuit of happiness, but over their range, scope, content, and application. 25 If the parameters of a debate are extremely general notions, such as Stout's platitudes and rights, they are adequate to get debate started, but not sufficient to resolve it, unless more specific notions are introduced, or matters of interpretation are settled, or casuistic technai are concocted in the meantime. Without such developments, the parties to such disputes share little more than a rhetorical style.

24 Thomas Kuhn, The Structure of scientific Revolutions (Chicago: University of Chicago Press, 1970); Richard Rorty, Philosophy and the Mirror of Nature, pp. 315-56; Richard Bernstein, Beyond Objectivism and Relativism (Philadelphia: Univ. of Pennsylvania Press, 1983), esp. part 2; Alasdair Maclntyre, "Epistemological Crises, Dramatic Narrative, and the Philosophy of Science", in G. Gutting, ed., Paradigms and Revolutions (Notre Dame: Univ. of Notre Dame Press, 1980).

25 For parallel views on the language of rights, see Christopher Lasch, "The Communitarian Critique of Liberalism", in C. Reynolds and R. Norman, eds., Community in America (Berkeley: Univ. of California Press, 1988), and Sheldon Wolin, "Revolutionary Action Today", in J. Rajchman and C. West, eds., Post-Analytic Philosophy (New York: Columbia Univ. Press, 1985). 
In Stout's defense it could always be argued that the aforementioned problems of interpretation and application need not be solved anterior to any dispute: they may emerge during the course of debate, through processes of "hermeneutic enrichment" rather than rational commensuration. This is true but, from the standpoint of liberal modernity, irrelevant. For "hermeneutic enrichment" to be a mode of rational conflict-resolution, a certain sort of attitude must prevail among potential disputants: a willingness to see serious disagreement settled by rational argument, which requires both a commitment to one's own moral standpoint as true and a willingness to let the convictions proper to that standpoint be challenged by other, incompatible and competing convictions. 26 For participants in such conflicts, the deliverances of rational argument are decisive: after alternative moral systems have been understood and appropriated, one's final allegiance rests with that system which has established itself, through argumentative inquiry, as the best to have emerged thus far. But liberal social orders are predicated on the idea that judgments about the best emergent system of moral belief and practice--judgements which will bank upon middle-level agreementscannot and should not be settled, definitively or provisionally. Ronald Dworkin has defined liberalism as the belief that justice is independent of any conception of the good life: justice is formal and procedural, setting the universal terms for conducting disputes in abstraction from the subject matter of such disputes. 27 In such a social and political climate, it is difficult to see how practices and institutions saddled with the responsibility of forming agents and/or citizens who wish their actions to be informed by the best possible reasons can flourish. The liberal social and political order systematically undercuts those tendencies that might provide fertile ground for limited moral agreement. 28 Davidsonian consensus and hermeneutic enrichment exist in the liberal order as formal, but not real possibilities.

My disagreement with Stout, then, is largely an empirical one. Davidson's quasi-transcendental argument establishes that no two linguistic communities can disagree on everything yet still both be identifiable as linguistic; the hermeneutic tradition advanced by Gadamer explodes the "myth of the framework" which equates incommensurability with incomprehensibility. But these a priori observations, even if they are

26 Alasdair Macintyre, "Relativism, Power, and Philosophy", in K. Baynes, J. Bohman, and T. McCarthy, eds., After Philosophy (Cambridge: M.I.T. Press, 1986), pp. 408-409.

27 Ronald Dworkin, "Philosophy and Politics", in Bryan Magee, ed., Men of Ideas (New York: Viking, 1978), p. 259.

28 Cf. Stanley Hauerwas, A Community of Character (Notre Dame: Univ. of Notre Dame Press, 1981), pp. 72-86; Barry Schwartz, The Battle for Human Nature (New York: Norton, 1987), Pp. 245-80. 
sound, do not ensure that every social and political order can sustain a significant rational agreement on moral matters, and they certainly do not ensure this consequence for individualistic liberalism. Whether they contingently do or not is a matter for detailed investigation; then let the sociological or historical chips fall where they may.

Stout is not starry-eyed about the liberal order in its present state: his critique of contemporary society in many ways parallels that of communitarians: 29

I have not demonstrated that our linguistic ecosystem is viable. Even if we do have sufficient agreement and conceptual wherewithal to support rational moral discourse we could still be too vicious and our institutions too corrupted to live well. (p. 219)

The idea that liberal society lacks any shared conception of the good is false, but this doesn't mean all is well. It could still be the case that politics, as the social practice of self-governance directed toward the common good, has begun to give way to merely bureaucratic management of competition for external goods. (p. 291)

But Stout persists in thinking that none of this is endemic to liberalism per se. He sees "corruption," the displacement of goods internal to practices by the external goods supplied by institutions, as a challenge which can be adequately surmounted by thin, Davidsonian consensus and the conceptual enhancements of effective hermeneutic consciousness. But if I am correct in insisting upon substantial "middlelevel" agreement as a condition for peaceful conflict-resolution, and Dreyfus is correct in viewing understanding as always involving the acquisition of nonformalizable skills through apprenticeship and training, then Stout leaves liberal society without two indispensable tools for solving its crisis: action-guiding premises for practical reasoning, and virtuous and discriminating agents for whom the dictates of practical reasoning carry weight.

A full account of the poverty of liberalism in this respect has yet to be written. Let two highly anecdotal examples suffice for the moment. In Moral Mazes: The World of Corporate Managers 30 Robert Jackall sketches a picture of a Weberian enclave where the rules which guide individual conduct within the organization differ radically from those which apply to home and hearth. The key maxim of many of Jackall's managers seems to be "Please the boss at all costs." The distinctions

29 Stout, pp. 231-32, 266-92.

30 Oxford: Oxford University Press, 1988. 
between pleasing and doing well for someone, as well as those between being good at one's profession and seeming good to one whose decisions can further one's fortunes, disappear for them. 31 It follows that for Jackall's managers qua managers the divide between internal and external goods has not softened, with the latter impinging upon the former; internal goods are unintelligible in such a context, except as rhetorical gobbledygook. 32 Yet if significant sectors of liberal society, imbued with the managerial ethos liberalism nourishes, forswear internal goods altogether, there is very little point in speaking of moral virtues or duties in those contexts: what ends internal to what practices could they serve? If Jackall's picture of management is even remotely accurate, the task facing liberalism is not the reinvigoration of practices in corporations, but acknowledging their disappearance. And how, apart from challenging liberal middle-level neutrality and proceduralism, can such practices be inserted into a Goffmanesque parade of manipulation and counter-manipulation?

Another example: Barry Sussman, in What Americans Really Think 33 argues that most Americans have not forsworn the precepts of the old, post-New Deal welfare liberal coalition for Ronald Reagan's even older economic liberalism. They remain committed to a decent social minimum, Social Security, the accountability of government to the governed in foreign and domestic policy, and "no more Vietnams." 34 Sussman supports these claims by a detailed analysis of public opinion polls; he is himself a reputable public opinion analyst and pollster. Yet, despite the overwhelming evidence he cites to show that Reagan has not commanded anything approaching an ideological mandate, his polls consistently reveal that people will vote their economic interests whatever their corresponding ideological convictions about justice or the common good. Voting one's pocketbook is a constant across class, ideological, and party lines. 35 If I read Sussman correctly, his research poses a

31 Q.v. Jackall, PP 19-20. "IB]ureaucratic work causes people to bracket, while at work, the moralities that they might hold outside the workplace or that they might adhere to privately and to follow instead the prevailing morality of their particular organizational situation. As a former vicepresident of a large firm says: 'What is right in the corporation is not what is right in a man's home or in his church. What is right in the corporation is what the guy above you wants from you. That's what morality is in the corporation"' (p. 6).

32 Cf. MacIntyre, After Virtue, Ch. 3.

33 New York: Pantheon, 1988.

34 Sussman, Part Three, passim.

35 Sussman, pp. 206-220. See especially the chart on p. 218 which documents the tendencies among many voters to vote for Reagan on self- 
considerable problem to Stout, insofar as Stout believes that the liberal polity possesses resources for transforming its institutions in a direction more hospitable to practices. This would minimally require a citizenry prepared to act on its own basic moral convictions, a citizenry for whom the deliverances of practical reasoning are decisive. Sussman's citizens, though they have "strong" convictions, characteristically abandon them when individual economic interests dictate. Yet for moral reason to be effective, for Davidsonian consensus, hermeneutic enrichment, and middle-level agreement to make a real difference, such convictions, however "strong," need to be more than notional. It may very well be the case that their ephemerality indicates a distinct lack of determinate middle-level content--that, in effect, much of what passes for heartfelt political belief in contemporary America is merely platitudinous. This too seriously compromises the optimism which permeates Stout's moral epistemology.

I reiterate: the examples above are anecdotal, a mere preface to an issue to be settled by far more detailed empirical analyses. But it is an empirical issue and a philosophically important one at that: whether or not modern liberal individualism and its various progeny can actually sustain the moral coherence that Stout and others grant to them in theory.

Stout contends that liberal society can, in principle, be other than it is. But it is not ultimately philosophical principle that will effect this sort of change: it is character. Whether modernity has a reserve of persons of good character, whether modernity in fact tends to undermine good character by making it fit awkwardly if at all within its dominant institutions, are questions slighted by Stout in Ethics After Babel, but nevertheless the questions that need to be acknowledged and answered if liberalism is to receive an adequate rational defense. ${ }^{36}$

interested economic grounds even when they believed that Mondale's policies were more equitable and prudent.

36 Special thanks must go to my colleagues Stephan T. Mayo, James Montmarquet, and Barbara Taranto, who read and commented upon this essay. An earlier version was presented at the Eastern Division meeting of the A.P.A., 28 December 1989, in Atlanta, Ga. 